\title{
EN EL PRINCIPIO ESTÁ EL FIN: DE HERÁCLITO A T.S. ELIOT
}

\author{
Miguel Á. Márquez Guerrero \\ Pablo L. Zambrano Carballo
}

1. El tema de este artículo es la relación de Four Quartets $(F Q)$ de T. S. Eliot con los fragmentos filosóficos de Heráclito, tanto en su contenido como en su estructura. Nuestro objetivo es hacer ver la influencia que la lectura de Heráclito ejerció en Eliot durante el periodo de composición de $F Q$ y que sus ecos aparecen en otras composiciones del poeta.

1.1. El análisis exhaustivo de esa fuente aclara en algunos puntos el pensamiento expuesto en $F Q$ y, sobre todo, permite proponer una estructura novedosa que explica su unidad. Sin desechar otras fuentes, este trabajo sitúa en su justo punto el límite de una de las tradiciones de las que parte Eliot: la cultura griega ${ }^{1}$. Por otro lado, presentamos un esquema básico que sustenta la unidad de la obra, al margen de las recurrencias temáticas y recursos compositivos ya señalados por la crítica (Gardner: 1978).

1.2. Desde la temprana "The Love Song of J. Alfred Prufrock" (1915), que se abre con una cita de Dante, T. S. Eliot antepone a muchos poemas epígrafes de procedencia muy variada, a los que el poeta parece conceder una función que va más allá de la boutade erudita. En su caso, los epígrafes y los numerosos fragmentos literales de otros autores dispersos por su poesía se convierten en piezas fundamentales para la comprensión del poema. ${ }^{2}$

1.3. En este sentido, las citas iniciales de dos fragmentos de Heráclito (22B 2 y 60$)^{3}$ y la traducción casi literal uno de ellos en el tercer cuarteto, "Dry Salvages" (DS 130), es un aviso que proporciona el poeta a los lectores para que no pasara desapercibido ese componente esencial de $F Q$ : Eliot, pues, reconoce su deuda con el filósofo griego. Por otra

\footnotetext{
${ }^{1}$ El interés de Eliot por el mundo clásico es manifiesto desde sus primeros poemas ("Gerontion") hasta el teatro: Sweeney Agonistes, definido por el autor como un melodrama aristofánico, se encabeza con una cita de Esquilo relativa a las Furias que persiguen a Orestes.

$2 "$ The function of the prefatory motto $[\ldots]$ is to set the mood or tone with reference to the symbols and images that occur within the poem proper" (Daiches: 1948, 113).

3 Inicialmente las citas preceden a "Burnt Norton" (BN), pues Eliot compuso el primer cuarteto en 1935 sin ninguna idea de integrarlo en un conjunto más amplio. Sólo cinco años más tarde, a razón de uno por año, decidió continuar con el tema de 'Burnt Norton' y escribir el resto de los cuartetos. Lo que conservamos hoy es evidentemente una unidad poética compuesta por cuatro poemas que, a su vez, son unidades en sí mismos. Por tanto, las citas de Heráclito, como veremos, no sólo afectan al primer cuarteto sino al conjunto del libro.
} 
parte, no sería inoportuno recordar que T. S. Eliot, además de literatura, cursó en Harvard estudios clásicos y filosofía y que su conocimiento de las lenguas clásicas era estimable.

1.4. Ahora bien, mucho más importante para estudiar la relación de Heráclito y $F Q$ es el principio de creación que consiste en utilizar el mito y las formas tradicionales para poner orden en el caos contemporáneo reflejado por la literatura. T. S. Eliot atribuye el hallazgo de este principio al Ulises de Joyce (Valverde: 1978); su operatividad en la composición de $F Q$ parece fuera de toda duda, aunque Eliot no recurre al mito y a las formas sino al pensamiento filosófico arcaico.

2. ¿Por qué es Heráclito precisamente un punto de referencia esencial para Eliot en $F Q$ ? ¿Qué encontró Eliot en Heráclito que pudiera servirle para poner orden en el caos vivencial de la realidad cotidiana?

2.1. Con Heráclito se da un cambio esencial en la cultura griega, en primer lugar, porque él y Parménides inician una vía especulativa no abordada antes por la filosofía de la naturaleza y, en segundo lugar, porque Heráclito presenta una voluntad firme y consciente de superar la cultura oral, trasmitida en versos que se recitaban en público (Eggers Lan: 1978, 314). Mientras que Parménides compuso su obra en hexámetros, Heráclito escribió en prosa su pensamiento; su objetivo no era ser conservado en la memoria oral de los poetas sino ser depositado como libro en el templo de Artemis (Diógenes Laercio IX, 5), ya que no existían bibliotecas cuando se escribían los primeros libros.

2.2. Se ha dicho que Eliot con $F Q$ pretende una vuelta al momento originario, restaurar los principios de una civilización que para el poeta se encamina a su ruina final. En el plano personal, esa vuelta no puede ser sino a la infancia; en el religioso, Eliot fija en Pentecostés el momento inicial. Por eso, en su reflexión sobre la palabra, Eliot se vuelve a la filosofía de Heráclito, en la que el logos es palabra original y razón ordenadora del mundo (Mondolfo: 1976, 156 y 159). Eliot encontró en Heráclito el "punto cero" de una cultura formada a imagen y semejanza del lenguaje escrito y leído. ${ }^{4}$

2.3. En segundo lugar, la aparición de $F Q$ (1942) culmina un proceso que se había iniciado antes y que adquiere en 1928 una formulación para la historia de la literatura en la declaración de Eliot de ser "clasicista en literatura, monárquico en política y anglocatólico en religión" (Prólogo de For Lancelot Andrewes). Estas palabras resultaban provocadoras en un poeta americano, de formación protestante y que había sentado con el Modernism las bases de la vanguardia en la poesía anglonorteamericana. Declararse "clasicista" implica una vuelta a la tradición, no sólo mediante la búsqueda de citas más o menos raras y de hallazgos lingüísticos que Pound y Eliot seleccionaban y combinaban o yuxtaponían en la etapa vanguardista. Ahora la poética de Eliot pretende un poema perfecto en estructura, con un tema bien definido y una organización lógica de sus partes, todo ello en clara contraposición a la estructura, tema y organización de su anterior gran poema, The Waste Land (1922). El

\footnotetext{
${ }^{4}$ Eliot declaró que se sintió atraído por la sugerencia de los fragmentos de Heráclito (Clubb: 1961, 120).
} 
resultado de esta poética $(F Q)$ dividió a la crítica. El ambiente universitario acogió la obra favorablemente porque, según sus detractores, permitía un fácil y brillante análisis en las aulas. Sin embargo, otra parte de la crítica recibió con recelo el poemario, porque suponía aparentemente un paso atrás, una vuelta a posiciones superadas por el Modernism. En $F Q$ se veía una pérdida de confianza en la poesía y una suplantación del don poético por la reflexión sobre temas históricos, religiosos y filosóficos. Así, $F Q$ ha sido tachado a veces de tedioso por su tono abstracto, de lúgubre por su escepticismo y de dogmático porque Eliot se nos presenta como portador de una verdad religiosa revelada, fruto de una búsqueda de la revelación y la purificación que se había iniciado mucho antes.

2.4. Heráclito ofrecía un paradigma a esa actitud de Eliot; Heráclito "el oscuro" se presenta como poseedor de una profunda verdad, desconocida para sus congéneres, y con la misión casi profética de difundirla. Esta actitud dogmática concuerda con su metodología, hasta cierto punto nueva: la razón está por encima de la experiencia sensorial. ${ }^{5}$ Así pues, no es nada extraño que Eliot cite el fragmento 22B 2, donde se oponen razón común e inteligencia particular, como encabezamiento de $F Q$.

2.5. Para llegar a esta razón común, el filósofo debe refutar los conocimientos particulares acumulados por la experiencia y para ello utiliza metodológicamente la paradoja: salud es enfermedad, invierno verano, el camino que sube el mismo que el que baja... La serie completa de estas paradojas es imagen de la armonía oculta que subyace bajo la aparente contraposición de contrarios, que son, según Kirk (1970, 260):

a) las mismas cosas que producen efectos opuestos (22B 9 y 13);

b) aspectos diferentes que justifican descripciones opuestas, pero que se engloban en una realidad única (22B 58 y 60);

c) contrarios que existen en la medida que se oponen (22B 65 y 111);

d) opuestos que se identifican simplemente porque se suceden (22B 67).

Eliot ha utilizado este tipo de oposiciones, algunas veces tal cual, pero con una diferencia esencial con respecto a Heráclito, quien afirma que la unidad, es decir, el ser se integra con la unión de los contrarios. En cambio, Eliot propone contrarios negados por la correlación neither...nor..., por ejemplo en "Burnt Norton"' (BN) 62 y ss.: neither from nor towards, neither arrest nor movement. Mediante estas dobles negaciones no se llega al ser sino a la negación de la realidad dada. ${ }^{6}$

\footnotetext{
5 "Su meta es despertar y llamar a los hombres a abrazar su ley de vida y a vivir en consecuencia. su pensamiento central es ético, y sólo porque la ley, a la que ha de someterse el hombre, es al mismo tiempo la ley del cosmos, su doctrina es también una cosmología" (Gigon: 1980, 221). Sobre la limitación del saber por experiencia, véase EC 82-83: "At best, only a limited value / In the knowledge derived from experience."

6 Sin embargo, para Eliot, en Ash-Wednesday, la "Dama" a la que se dirige la invocación de la segunda parte del poema representa, en un contexto místico, la integración del ser mediante la unión de los contrarios: "Lady of silences / Calm and distressed / Torn and most whole / Rose of memory / Rose of forgetfulness / Exhausted and life-giving / Worried reposeful / The single Rose / Is now the Garden / Where all loves end / Terminate
} 
2.6. Eliot lleva a cabo una profunda reflexión sobre el tiempo y la eternidad; la experiencia vital, en la que la memoria y la esperanza, el olvido y el miedo juegan un decisivo papel para la constitución de la continuidad temporal de pasado, presente y futuro, será superada por la fe en la razón sobre los sentidos, la fe en el fuego purificador y la fe en la Palabra, equivalente al Logos griego, por encima de las palabras (=poesía) en un tiempo que engloba pasado, presente y futuro. Este último es uno de los temas que articulan $F Q$ y gran parte de la obra de Eliot. El poeta, en su intento de purificar el lenguaje (LG 127) concluye que la poesía no importa (EC 70-71). ${ }^{7}$ La búsqueda del logos griego como solución para superar tal estado es evidente en $F Q$, pero se trata en realidad de la misma solución que Eliot proponía ya en Ash-Wednesday - V (1930):

If the lost word is lost, if the spent word is spent

If the unheard, unspoken

Word is unspoken, unheard;

Still is the unspoken word, the Word unheard,

The Word without a word, the Word within

The world and for the world;

And the light shone in darkness and

Against the Word the unstilled world still whirled

About the centre of the silent Word.8

La meta final que nos propone Eliot es la vuelta al punto de partida, para no repetir personalmente la misma vida y colectivamente la misma historia, llenas ambas de miserias y frustraciones. En primer lugar, la vuelta a la infancia; en segundo, la vuelta al momento en que se inicia la historia de la religión: la llegada del Espíritu Santo como fuego iluminador en Pentecostés; y, por último, para la poesía, la vuelta a la palabra originaria.

2.7. A su vez, Heráclito, condicionado por su contexto histórico, debía responder al principal problema de su tiempo: la contradicción entre el ser y el movimiento. Para ello ofrece una metáfora que no pretende solucionar la aporía pero que ilumina nuestro concepto de la realidad; es la imagen del río en 22B 12 y 49a: en cada nuevo baño, encontramos el río (ser) pero las aguas son distintas (movimiento) y, así, ese río es el mismo y no es el mismo. Ser y movimiento son facetas de un único cosmos. Al aceptar el ser, Heráclito

torment / Of love unsatisfied / The greater torment / Of love satisfied / End of the endless / Journey to no end / Conclusion of all that / Is inconclusible / Speech without word and / Word of no speech / Grace to the Mother / For the Garden / Where all love ends."

7 El pesimismo y la insatisfacción de Eliot acerca de las "palabras" le lleva a afirmar: "every attempt / Is a wholly new start, and a different kind of failure / Because one has only learnt to get the better of words / For the thing one no longer has to say, or the way in which / One is no longer disposed to say it. And so each venture / Is a new beginning, a raid on the inarticulate / With shabby equipment always deteriorating..." (EC 174-180).

${ }^{8}$ La antítesis entre "word" (palabra) y "Word" (Palabra) permite obviar cualquier comentario al respecto. Sí es necesario señalar la orientación cristiana que Eliot da a un fragmento que, por lo demás, coincide con las ideas de Heráclito acerca del logos como razón ordenadora. Tal matiz cristiano es esencial asimismo para la correcta comprensión de $F Q$. 
renuncia a la creación. El ser no puede ser creado ni destruido; ahora bien, el movimiento implica una línea temporal de pasado, presente y futuro. De esta manera, encontramos en 22B 30 una continuidad temporal ilimitada en la que el movimiento no altera el equilibrio del ser ("fuego siempre vivo que se enciende según medida y se apaga según medida"), siempre igual a lo largo del tiempo (Mondolfo: 1976, 252).

2.8. Los elementos que constituyen el cosmos (tierra, agua, aire y fuego) sufren un proceso de intercambio constante que no afecta al equilibrio. Heráclito no presenta a ninguno como elemento originario del que derivan los demás pero llega a identificar el fuego y el logos, la razón que ordena el mundo (García Calvo: 1985, 243). ${ }^{9}$ Esa preeminencia aparente del fuego y el intercambio de elementos hicieron concebir a los estoicos una idea que atribuyeron a Heráclito: en un momento de la historia cósmica, el fuego terminará absorbiendo a todos los seres concretos y superará el estado de discordia entre opuestos con la unidad (Heráclito 22B 66). Más tarde esta conflagración universal, una especie de holocausto, ajena a Heráclito, tuvo su esperable reinterpretación cristiana (Kirk: 1970, 285).

2.9. Eliot la utilizó en su obra, identificando fuego originario y fuego purgativo, fuego como razón ordenadora y fuego pentecostal que ilumina los espíritus. Esta reinterpretación por parte de Eliot se explica si tenemos en cuenta que desde los años de Harvard su lectura de Heráclito y sus lecturas místicas corrieron parejas (Gordon: 1989, 141-142). Al margen del fuego, en las paradojas del filósofo griego y en sus ideas acerca del logos encontró Eliot un material fácilmente convertible a un sentido místico, caracterizado por un estilo paradójico y antitético.

3. En los primeros versos (BN 1-10) se presenta sintéticamente el proceso que a lo largo del libro nos lleva desde la linealidad del tiempo al concepto de eternidad; con esos versos intentaremos demostrar más abajo que la influencia de Heráclito sobre $F Q$ no se da sólo en ciertos temas filosóficos sino que Eliot se sirve de su filosofía para fijar la estructura del poemario. Por ahora, nos vamos a limitar al análisis de otros dos momentos de BN en los que se vislumbran las palabras de Heráclito.

\subsection{BN 62-67:}

At the still point of the turning world. Neither flesh nor fleshless;

Neither from nor towards; at the still point, there the dance is,

But neither arrest nor movement. And do not call it fixity,

Where past and future are gathered. Neither movement from nor towards,

Neither ascent nor decline. Except for the point, the still point,

There would be no dance, and there is only the dance.

Heráclit. 22B 65 y 67 :

\footnotetext{
${ }^{9}$ Esta identificación entre "fuego" y logos puede, sin embargo, matizarse. El fuego, cuyas transformaciones dan lugar al resto de los elementos, es constituyente material del universo, a diferencia de la razón, que es constituyente estructural. La identificación entre ambos conceptos procede del hecho de que este fuego se enciende y se apaga "según medida", es decir, según la razón.
} 


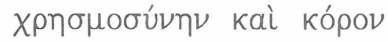

Indigencia hartura.

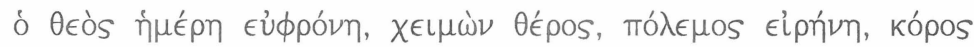 \\ $\lambda \iota \mu o ́ s . .$.
}

El Dios [es] día-noche, invierno-verano, guerra-paz, hartura-hambre... ${ }^{10}$

Los opuestos de Eliot, quizás especialmente ascent/decline, recuerdan la serie de contrarios de Heráclito, aunque con una diferencia (§ 2.5.): la doble negación de Eliot se aleja del sentido de la armonía de contrarios de Heráclito. La explicación de esta diferencia esencial puede hallarse en el carácter ascético de la primera parte del libro, señalado por la crítica. Otros opuestos negados aparecen en BN 92-96 y 99. A su vez, la unidad de los contrarios es sugerida en LG 174: "United in the strife which divided them."

Ahora bien, junto al tema de la oposición de contrarios, ese pasaje de Eliot plantea el problema del movimiento en relación con el tiempo y la eternidad. Las imágenes utilizadas son la rotación del mundo en torno a un punto inmóvil y el baile. Más adelante se recoge la paradoja del ser y el movimiento con la metáfora de un jarrón chino: "as a Chinese jar still / Moves perpetually in its stillness" (BN 142-143). Ese punto inmóvil que permite el movimiento es cifra de la eternidad puntual que engloba el curso de pasado, presente y futuro; ${ }^{11}$ la influencia de Heraclit. 22B 30 sobre esta idea se desarrolla en $§ 6$.

\subsection{BN 122-126:}

This is the one way, and the other

Is the same, not in movement

But abstention from movement; while the world moves

In appetency, on its metalled ways

Of time past and time future.

Heraclit. 22B 60:

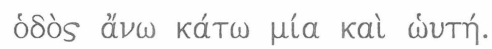

El camino hacia arriba [y] hacia abajo [es] uno solo y el mismo.

\footnotetext{
10 Para los textos griegos, seguimos la edición de Diels (1951-1952); como una simple ayuda para su comprensión, recogemosdespués del texto griego la traducción propuesta por Mondolfo (1976).

${ }^{11} \mathrm{La}$ imagen de la rotación alrededor de un punto inmóvil (del movimiento y del ser) es clara en los versos de Ash-Wednesday citados arriba: "Against the Word the unstilled world still whirled / About the centre of the silent Word" (énfasis añadido). Sin referirse directamente a él, B. C. Southam (176) insinúa la influencia de Heráclito en dicho pasaje de Ash-Wednesday al comentar que Eliot utiliza "Word" en el sentido del primitivo logos griego y, en otro nivel, en un sentido también cercano a las palabras de Juan 1, 1: "En el principio era el Verbo, y el Verbo era con Dios, y el Verbo era Dios", es decir, como razón ordenadora del mundo. El que ambos orígenes sean perfectamente compatibles como fuentes directas de Eliot demuestra una vez más la reinterpretación cristiana que el poeta hizo de parte del pensamiento de Heráclito.
} 
Estos versos de Eliot se han interpretado como una alusión humorística a las escaleras que suben y bajan en el acceso al metro. Aunque sea correcto ese comentario, es evidente que Heracilt. 22B 60 ha iluminado la reflexión de Eliot a partir no sólo de esas escaleras sino tambien de los dos sentidos de las vías. ${ }^{12}$ La identidad de los caminos de subida y bajada se asocia espontáneamente a la ausencia de movimiento; frente a ese estado de unidad fuera del tiempo, el mundo se mueve ("the world moves...") en una línea temporal que discurre del pasado al porvenir.

4.1. EC 1 y 209:

In my beginning is my end...

...In my end is my beginning.

Herácilt. 22B 103:

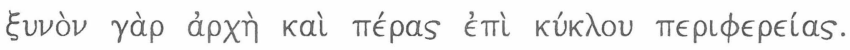

Es común (=coincidente), pues, el principio y el fin sobre la circunferencia de un círculo.

Mientras que $\mathrm{BN}$ se inicia con la fórmula de la eternidad englobante, EC anuncia en su primer y último verso con una especie de composición en anillo la coincidencia de principio y fin en el tiempo cíclico de las estaciones y de las fases de generación y muerte. ${ }^{13}$ De esta manera, la idea de ciclo sirve a Heráclito para afirmar la unidad de contrarios y en Eliot para restaurar el momento original. No es extraño que, desde un punto de vista histórico, EC se haya interpretado como una vuelta de Eliot al lugar desde el que, en el siglo XVII, partieron

\footnotetext{
12 No parece haberse reparado en que Eliot recrea la paradoja de Heráclito de forma más clara en The Family Reunion (1939) que en $F Q$ : "We do not like to climb a stair, an find that it takes us down." (348). Además, la reminiscencia heraclítea de esta imagen se ve reforzada por otra que le sigue inmediatamente: "We do not like to walk out of a door, and find ourselves back in the same room". El movimiento hacia arriba y el movimiento hacia abajo, hacia adelante y hacia atrás, son en realidad la ausencia de movimiento. Todo esto refuerza la importancia del filósofo griego en la composición de $F R$, sobre todo teniendo en cuenta que se escribió después de $\mathrm{BN}$ e inmediatamente antes del resto de los Cuartetos, funcionando así como una especie de puente que salva la distancia de 5 años entre el primer cuarteto y el resto. Además, como veremos, las conexiones con $F Q$ en este sentido van aun más allá.

$13 \mathrm{El} \mathrm{comienzo} \mathrm{de} \mathrm{EC} \mathrm{("in} \mathrm{my} \mathrm{beginning} \mathrm{is} \mathrm{my} \mathrm{end...")} \mathrm{y} \mathrm{el} \mathrm{final} \mathrm{("...in} \mathrm{my} \mathrm{end} \mathrm{is} \mathrm{my} \mathrm{beginning")} \mathrm{provienen}$ directamente del lema en francés de María Estuardo "En ma fin est mon commencement". Sólo el verso final de $\mathrm{EC}$ coincide con el original francés. Al invertir el orden del lema al principio del cuarteto, Eliot juega con una aparente paradoja que inmediatamente nos remite a Heráclito. Por otra parte, no es la única vez que Eliot recurre a tal imagen. De nuevo FR nos ofrece un ejemplo: "HARRY.... feel quite happy, as if happines / Did not consist in getting what one wanted / Or in getting rid of what can't be got rid of / But in a different vision. This is like an end. AGATHA. And a beginning. Harry, my dear, / I feel very tired, as only the old feel. The young feel tired at the end of an action-- / The old at the beginning..." (334 - énfasis añadido). No es éste momento para analizar $F R$, pero sí para señalar la semejanza de este fragmento con Heráclit. 22B 88: "Como una misma cosa se dan en nosotros vivo y muerto, despierto y dormido, joven y viejo. Pues lo uno, convertido, es lo otro, y lo otro, convertido, es lo uno a su vez." (énfasis añadido). Sobre la paradoja "despierto/dormido" vuelve también Eliot en FR: "We do not like what happens when we are awake, because it too / closely resembles what happens when we are asleep." (348). Sobre lo vivo y lo muerto afirma, muy al modo de Heráclito, que "that which is only living / Can only die." (BN 138-139).
} 
sus antepasados hacia América. La vuelta de Eliot a Europa completaría el ciclo (Bergsten: 1960, 209-210).

4.2. Después de la presentación del tiempo de los ciclos, la aproximación en EC al mundo de la aldea permite observar el rito del matrimonio y Eliot aprovecha la oportunidad para recordar la concordia de opuestos que giran alrededor de un fuego que es al mismo tiempo razón ordenadora; EC 31-33:

Two and two, necessarye coniunction

Holding eche other by the hand or the arm

Wiche betokeneth concorde. Round and round the fire...

Heraclit. 22B 8 y 10 :

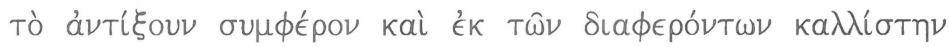

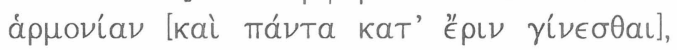

Lo que se opone es concorde y de lo discordante [se forma] la más bella armonía y todo se engendra por la discordia.

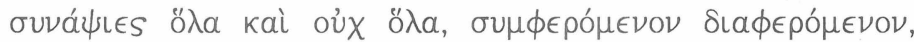

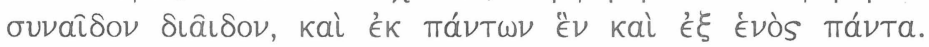

Conexiones: enteros y no enteros, convergente divergente, consonante disonante; de todos uno y de uno todos.

Unido a la concordia de opuestos, la sucesión de las generaciones, que inspira la primera parte de EC, tiene su paralelo en Heráclit. 22B 20; sin embargo, es la imagen de la muerte del hombre y el estiércol de Heráclit. 22B 96 la que ha dejado una huella más clara en el "Dung and death" con el que concluye la reflexión sobre las estaciones (EC 49).

4.3. EC $147-151$ y 156 :

The wounded surgeon plies the steel

That questions the distempered part;

Beneath the bleeding hands we feel

The sharp compassion of the healer's art

Resolving the enigma of the fever chart.

And that, to be restored, our sickness must grow worse.

Heraclit. 22B 58 y 111 :

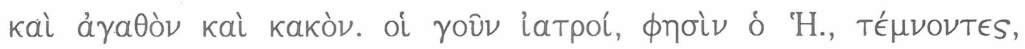

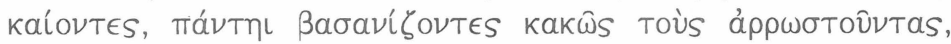

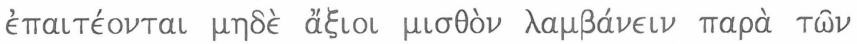

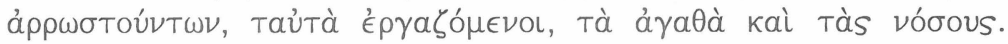

Y bien y mal [son una cosa sola]: Los médicos, pues -dice Heráclito-, al cortar, quemar y torturar por todas partes y de mal modo a los enfermos, piden 
además recibir una remuneración de los enfermos, a pesar de no merecer nada, ellos que producen idénticamente los beneficios y los sufrimientos.

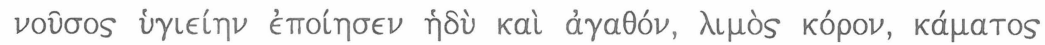

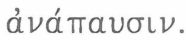

La enfermedad suele hacer suave y buena la salud, el hambre la saciedad, la fatiga el reposo.

Con este paralelo de EC y Heráclito, abandonamos la influencia literaria en la organización del conjunto o en ideas generales y alcanzamos quizás un préstamo literario de una imagen muy concreta, la del médico que aparentemente haciendo daño cura. Al margen de ese préstamo, el conjunto de la alegoría de la sección IV de EC depende de John Cleveland (Gardner, 109). En cuanto a la función de la metáfora de $F Q$, parece bastante alejada del sentido del fragmento de Heráclito: la identidad de contrarios. El objetivo de Eliot, mediante una serie de "conceits" siguiendo el estilo de John Donne (Murray: 1991, 65), es mostrar la importancia del sufrimiento en el hombre (reflejo del de Cristo en la cruz) para alcanzar la dicha eterna. Esta declaración abiertamente religiosa y cristiana por parte de Eliot se corresponde con el tono ascético de buena parte del poema y vuelve a recordarnos cuál es el carácter esencial de $F Q$. Eliot vuelve "a lo divino" la imagen de Heráclito y el estilo paradójico del filósofo griego le sirve para expresar ciertas ideas ascético-místicas. ${ }^{14}$

5.1. Heráclit. 22B 12 y 49a:

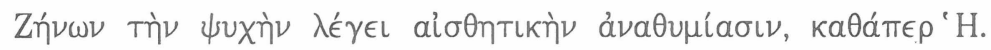

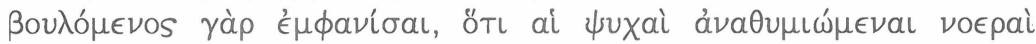

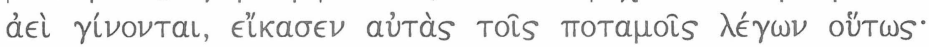

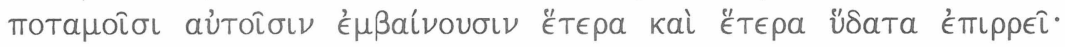

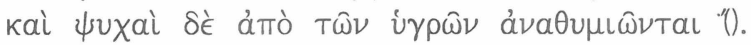

(Zenón llama al alma exhalación sensible, de acuerdo con Heráclito; pues [éste] queriendo mostrar que las almas que salen por exhalación se vuelven siempre nuevas [nearaiv], las comparó con los ríos diciendo lo siguiente: A los que ingresan en los mismos ríos sobrevienen otras y otra aguas; y salen almas por exhalación de las cosas húmedas.

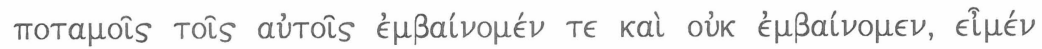
T€ kai oủk $\epsilon \hat{\imath} \mu \epsilon \nu$.

En los mismos ríos ingresamos y no ingresamos, estamos y no estamos.

En DS, Eliot recurre continuamente al río, en principio, símbolo del tiempo: "reminder / Of what men chose to forget" (DS 8-9) y después símbolo de nuestra propia esencia

\footnotetext{
14 Prueba de ello es también el que una paradoja como "if to be warmed, then I must freeze" (EC 163), utilizada por Eliot en un contexto ascético, pueda relacionarse convincentemente con Heráclit. 22B 126: "Las cosas frías se calientan, lo caliente se enfría, lo húmedo se seca, lo árido se humedece." El que Eliot recurra a tal antítesis sólo unos versos después de la imagen del cirujano que cura dañando refuerza tal relación.
} 
temporal: "the river is within us" (DS 15). De la misma manera que el río de Heráclito existe pero sus aguas no son las mismas porque no deja de fluir, así también Eliot afirma en el último cuarteto: "Knowing myself yet being someone other" (LG 100) y compara al hombre con los pasajeros de un tren o un barco que pierden su identidad con el movimiento y el tiempo; ${ }^{15}$ DS $137-140$ y $149-154$ :

Fare forward, travellers! not escaping from the past

Into different lives, or into any future;

You are not the same people who left that station

Or who will arrive at any terminus,

'Fare forward, you who think that you are voyaging;

You are not the same who saw the harbour

Receeding, or those who will disembark. ${ }^{16}$

\subsection{DS 129:}

And the way up is the way down, the way forward is the way back

Heraclit. 22B 60:

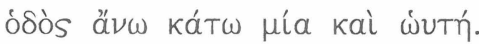

El camino hacia arriba [y] hacia abajo [es] uno solo y el mismo.

Naturalmente la primera parte de DS 129 es la traducción literal de Heráclit. 22B 60, uno de los dos fragmentos citados como lemas del libro y al que se alude también en BN 122126 (3.2). La segunda parte de DS 129 corrobora que la imagen procede tanto de las escaleras de subida y bajada al metro como de los dos sentidos de las vías del tren.

6.1. Heráclit. 22B 62 y 76 :

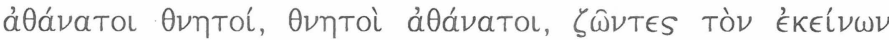

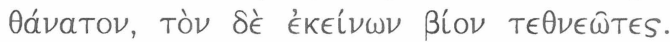

Inmortales mortales, mortales inmortales, viviendo la muerte de aquéllos, muriendo la vida de aquéllos.

\footnotetext{
15 Esta imagen conctreta compaña a Eliot hasta The Cocktail Party (1949): "UNIDENTIFIED GUEST....We must remember / That at every meeting we are meeting a stranger" (385). En cuanto al famoso fragmento del río (Heráclit. 22B 12) es de nuevo el teatro el que nos proporciona más pistas soble la influencia de Heráclito en T. S. Eliot. La cita se ha interpretado de maneras muy diversas y equivocadas, casi siempre de memoria, hasta el punto de que la versión más difundida es una interpretación errónea de Platón en el Crátilo 402a en donde afirma que "dice en alguna parte Heráclito que todo fluye y nada permanece, y asemejándolo a la corriente de un río, dice que no podrás entrar dos veces en el mismo río" (Alianza, 125-126). Críticos como Johnson Sweeney (779) persisten en el error: "For in the Heraclitean saying, no man ever bathes twice in the same stream". En FR Eliot, mediante el personaje de Agatha, recoge la cita errónea de Platón y convierte el "río" en "puerta"; el espíritu heraclíteo es, sin embargo, evidente: "We do not pass twice through the same door / Or return to the door through which we did not pass."

16 Otra posible fuente directa de estos versos puede rastrearse asimismo en el segundo fragmento de Epicarmo, también incluido en Diels (Clubb: 1961, 24).
} 


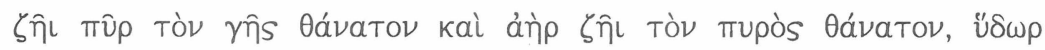

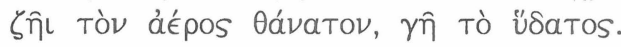

Vive el fuego la muerte de la tierra, y el aire vive la muerte del fuego, el agua vive la muerte del aire, la tierra la del agua.

Heráclito en el fragmento 62 expresa mediante la idea del intercambio de vida y muerte entre los opuestos su mutua identidad; en el fragmento 77, parece aplicar este pensamiento a las relaciones cosmológicas en el ciclo de conversión recíproca de los elementos: tierra $\rightarrow$ fuego $\rightarrow$ aire $\rightarrow$ agua $\rightarrow$ tierra... Eliot en LG 54-57 concluye cada una de las tres primeras estrofas de ese movimiento con las siguientes sentencias:

This is the death of air.

This is the death of earth.

This is the death of water an fire.

El tránsito de vida y muerte puede verse además en $L G$ 230: "We are born with the dead".

6.2. $L G$ 144-146 y 203-206:

From wrong to wrong the exasperated spirit

Proceeds, unless restored by that refining fire

Where you must move in measure, like a dancer'.

The only hope, or else despair

Lies in the choice of pyre or pyre-

To be redeemed from fire by fire.

Heraclit. 22B 65 y 66 :

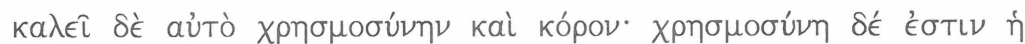

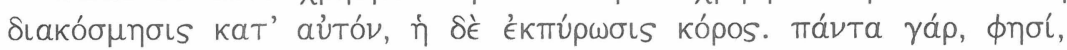

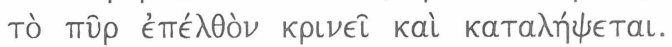

y lo llama:] "indigencia hartura" [indigencia, según él, es el ordenamiento del cosmos, hartura la conflagración]. "Todas las cosas, pues, [dice] el fuego al sobrevenir juzgará y agarrará".

Eliot identifica el fuego originario y el fuego purgativo que devuelve al punto cero; esta restauración pretende evocar el momento en el que el fuego pentecostal ilumina los espíritus. La idea es similar a la atribuida falsamente a Heráclito: la diversidad del cosmos basada en la oposición de contrario será compensada con una vuelta a la unidad en el fuego, quedando el cosmos subsumido en la razón ordenadora. Este proceso se repite cíclicamente en el llamado gran año, período en el que fuego restablece el orden y la unidad. Se debe observar que además del refining fire y pyre, Eliot complementa la acción de move con in measure, similar al fuego de Heráclito que "se enciende y se apaga según medida" (Heraclit. 22B 30). 
7. La crítica ha analizado las relaciones complejas y el hilo conductor de $F Q$, el tiempo y la eternidad. Se han aislado cinco partes con los siguientes temas principales: I) tiempo y eternidad; II) insatisfacción; III) vía purgativa; IV) invocación a la divinidad; y V) dificultad de la poesía y salud espiritual. No pretendemos refutar este análisis ${ }^{17}$ pero creemos que la influencia de Heráclito en $F Q$ es también estructural y que su comprensión permite proponer una organización unitaria y simple de $F Q$ en conjunto. Los primeros versos del libro nos dan la clave, BN 1-5:

Time present and time past

Are both perhaps present in time future,

And time future contained in time past.

If all time is eternally present

All time is unredeemable.

Eliot recoge las tres instancias temporales: pasado, presente y futuro, sentidas como un proceso lineal. Pero el poeta nos advierte desde el principio que realmente esas tres instancias están siempre presentes en una eternidad puntual, momentánea. Véase también BN 146-149:

Or say that the end precedes the beginning, And the end and the beginning were always there Before the beginning and after the end.

And all is always now.

Compárese con Heraclit. 22B 30 y 103:

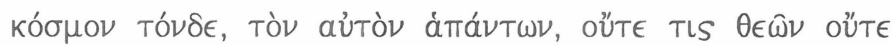

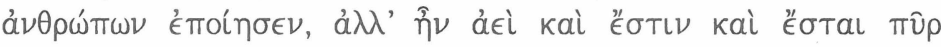

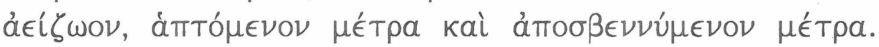

Este cosmos, uno mismo para todos los seres, no lo hizo ninguno de los dioses ni de los hombres, sino que siempre ha sido, es y será fuego eternamente viviente, que se enciende según medidas y se apaga según medidas.

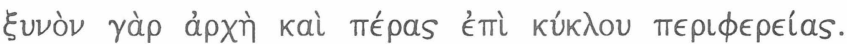

Es común (=coincidente), pues, el principio y el fin sobre la circunferencia de un círculo.

El cosmos, aparentemente variable, es, sin embargo, constante en la medida en que todo es "fuego siemprevivo". La apariencia temporal de los cambios queda subsumida en la eternidad del fuego. Por otra parte, a la coincidencia de principio y fin nos referíamos en

\footnotetext{
$17 \mathrm{Ni}$ otros, igualmente interesantes, como el de John M. Bradbury (257ss) que, siguiendo el hilo conductor de Heráclito, propone que cada cuarteto está dominado por uno de los elementos heraclíteos: aire (BN), tierra (EC), agua (DS) y fuego (LG).
} 
4.1.; en BN 146-149, el punto cero queda fuera de la línea o círculo entre principio y fin. Eliot con $F Q$ lleva a cabo una reflexión sobre el tiempo y la eternidad y utiliza ese esquema conceptual de cuatro partes en el que las tres instancias temporales (pasado, presente y futuro) confluyen en el punto de eternidad. Consecuentemente, Eliot estructura $F Q$ de la siguiente manera.

\section{BN pasado \\ EC presente \\ DS futuro \\ LG eternidad}

7.1. BN esta consagrado al pasado bajo dos imágenes: la memoria y la infancia. Eliot opone razón, siempre fuera del tiempo, y memoria, necesariamente temporal. Sin embargo, admite que el único camino para superar el tiempo pasa por la asunción del tiempo, primariamente como memoria del pasado; BN 83-90:

Time past and time future

Allow but a little consciousness.

to be conscious is not to be in time

But only in time can the moment in the rose-garden,

The moment in the arbour where the rain beat,

The moment in the draughty church at smokefall

Be remembered; involved with past and future,

Only through time time is conquered. ${ }^{18}$

7.2. EC dedica su atención al presente en el que coinciden el principio y el fin de los ciclos y estaciones. Obsérvese que esta idea circular está todavía muy lejos de alcanzar el enunciado de la eternidad fuera del tiempo como confluencia de pasado, presente y futuro; los ciclos y las estaciones son esencialmente temporales. Además Eliot reflexiona sobre la poesía desde la perspectiva de su personal aquí y ahora; EC 182-185:

So here I am, in the middle way, having had twenty years-

Twenty years largely wasted, the years of l'entre deux guerres-

Trying to learn to use words, and every attempt

Is a wholly new start, and a different kind of failure

7.3. El futuro es el objeto de DS mediante la recurrencia de diversos temas: el viaje (DS 130ss), la espera de las mujeres de los marinos ("Lying awake, calculating the future", DS

\footnotetext{
18 La superación del tiempo "mortal" para alcanzar la eternidad está en el fondo del mito del eterno retorno en el que se sitúan los Cuartetos y, en particular, el interés de Eliot por Heráclito: "...cualquier acción dotada de sentido llevada a cabo por el hombre arcaico, una acción real cualquiera, es decir, una repetición cualquieri. de un gesto arquetípico, suspende la duración, excluye el tiempo profano y participa del tiempo mítico." (Eliade: 1984, 42).
} 
40), la adivinación del porvenir en la sección V... Tampoco faltan referencias concretas al futuro (DS 71-72, 126) o a la evolución (DS 87-88).

7.4. Por último, LG representa la consumación de esa eternidad puntual, fuera del tiempo, en la que coinciden pasado, presente y futuro, a la manera del "fuego eternamente viviente" de Heráclit. 22B 30. Los primeros versos de LG son suficientemente explícitos:

Midwinter spring is its own season

Sempiternal though sodden towards sundown

Suspended in time, between pole and tropic.

When the short day is brightest, with frost and fire,

The brief sun flames the ice, on pond and ditches,

In windless cold that is the heart's heat,

Reflecting in a watery mirror

A glare that is blindness in the early afternoon.

And glow more intense than blaze of branch, or brazier,

Stirs the dumb spirit: no wind, but pentecostal fire

In the dark time of the year.

No obstante, más allá de ese enunciado de eternidad fuera del tiempo, LG culmina con la recuperación del momento originario, de la unidad a través del fuego (LG 252-259).

8. En conclusión, la lectura de los fragmentos de Heráclito influyó decisivamente en la composición de $F Q$. En primer lugar, la filosofía de Heráclito sobre el tiempo y la eternidad sirve de elemento organizativo en la estructura original de los cuatro cuartetos. En segundo lugar, el estilo antitético de los fragmentos, las paradojas y oposiciones, son en $F Q$ un rasgo de estilo esencial. Por último, en cuanto al contenido, Eliot recurre a tópicos como los del río, pero también a imágenes muy singulares: el camino que sube y baja, el cirujano que cura dañando, etc. Por otra parte, la influencia del filósofo griego se extiende también a obras como The Cocktail Party y, muy especialmente, The Family Reunion, cuya fecha de composición (1939) nos permite situarla como enlace entre BN y el resto de los cuartetos. 


\section{BIBLIOGRAFÍA}

Bergsten, Staffan (1960): Time and Eternity. A Study on Structure and Symbolism of T. S. Eliot's 'Four Quartets', Stockholm, Svenska Bokförlaget.

Bradbury, John M. (1951): "Four Quartets: The Structural Symbolism", Sewanee Review, 59, Spring, pp. 254-270.

Clubb, Merrel D. (1961): "The Heraclitean Element in Eliot's Four Quartets", Philological Quarterly, January, 19-33, vol. XL, n. 1, pp. 19-33.

Daiches, David (1948): Poetry and the Modern World, Chicago, University of Chicago Press.

Diels, H. (1951-1952): Die Fragmente der Vorsokratiker, I-III, Berlín.

Eggers Lan, Conrado y Juliá, V.E. (1978): Los filósofos presocráticos I, Madrid, Gredos.

Eliade, Mircea (1984): El mito del eterno retorno, Madrid, Alianza.

Eliot, T. S. (1928): For Lancelot Andrewes, Garden City NY, Doubleday, Doran.

Eliot, T. S. (1969): The Complete Poems and Plays, London - Boston, Faber \& Faber.

García Calvo, Agustín (1985): Razón común. Heraclito, Madrid, Lucina.

Gardner, Helen (1978): The Composition of 'Four Quartets', London.

Gigon, Olof (1980): Los orígenes de la filosofía griega, Madrid, Gredos.

Gordon, Lyndall (1989): Eliot's Early Years, Oxford University Press.

Kirk, G.S. y Raven, J.E. (1970): Los filósofos presocráticos, Madrid, Gredos.

Marcovich, M. (1968): Heraclitus. Texto griego y versión castellana. Editio minor, Mérida.

Mondolfo, Rodolfo (1976): Heráclito. Textos y problemas de su interpretación, México, Siglo veintiuno.

Murray, Paul (1991): T. S. Eliot and Mysticism, New York, St. Martin's Press.

Valverde, José María, ed. y trad. (1978): T. S. Eliot. Poesías reunidas (1909-1962), Madrid, Alianza.

Southam, B. C. (1990): A Student's Guide to the Selected Poems of T. S. Eliot, London Boston, Faber \& Faber.

Sweeney, James Johnson (1941): "East Coker: A Reading", Southern Review, 6, Spring, 771-791. 
